\title{
Closure of duodenal ulcer perforation using a novel endoloop device with a single- channel gastroscope after failed laparoscopic repair
}

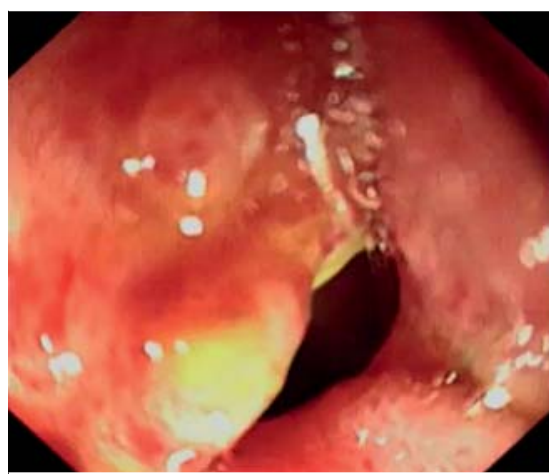

- Fig. 1 A large perforation of an ulcer located at the anterior wall of the duodenal bulb after the failure of laparoscopic closure in a 76-year-old man.

Patients with duodenal ulcer perforation regularly undergo conversion to open surgical repair after the failure of laparoscopic closure [1]. We report the use of a novel endoloop device with a singlechannel gastroscope for the closure of a duodenal ulcer perforation after failed laparoscopic repair.

A 76-year-old man underwent laparoscopic repair of a perforated duodenal bulb ulcer. However, he presented with abdominal pain and fever 8 days after surgery. Gastroscopy revealed a perforation of approximately $1.0 \mathrm{~cm}$ in size 10 cated at the anterior wall of the duodenal bulb ( $\triangleright$ Fig. 1). A novel LeCamp endoloop ( $\triangleright$ Fig. 2; Leo Medical, Changzhou, China) was inserted into the duodenal bulb by forceps through the single-channel therapeutic endoscope. After adjustment of the endoloop's location and angle, it was anchored onto the full thickness of the edge of the perforation with the clip ( $\mathbf{F i g} \cdot \mathbf{3}$ a). Several additional clips were then inserted to hold the endoloop at different sides of the margin ( $\triangleright$ Fig.3b). The delivery system was then inserted. The removable hook ( $\triangleright$ Fig. 3 c) was connected with the endoloop, which was tightened by slight pulling together of all the clips ( $>$ Fig. $3 \mathbf{d}$ ). The delivery system was subsequently

removed from the endoloop and the perforation was completely closed. A gastroduodenal decompression tube was placed as the last step ( $\triangleright$ Fig. $\mathbf{3 e}$ ). With relieved abdominal pain and fever, the patient's postoperative recovery was uneventful.

The LeCamp ligation device - a novel endoscopic product using the purse-string suture idea - has been developed from the method for closing larger perforations that used a nylon loop combined with hemostatic clips. It can be applied easily using the single working channel of conventional endoscopes and its loop does not need to be preloaded prior to insertion. The LeCamp endoloop significantly facilitates the accurate closure of lesion defects resulting from endoscopic full-thickness resection [2]. In the case described here, we used the novel endoloop and metallic clips with a singlechannel gastroscope to close a duodenal ulcer perforation after failed laparoscopic repair, which suggests that this new technique may be a simple and feasible method for closure of perforations in the gastrointestinal tract.

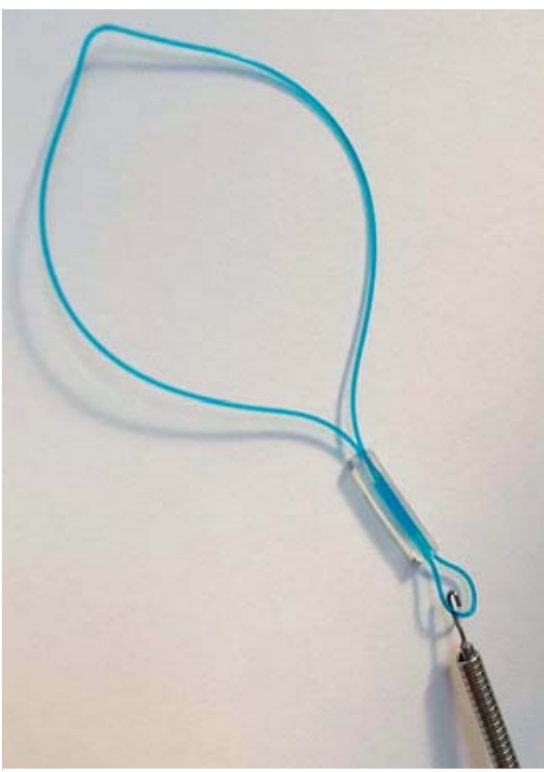

Fig. 2 The LeCamp endoloop.

Endoscopy_UCTN_Code_TTT_1AO_2AC

Competing interests

None

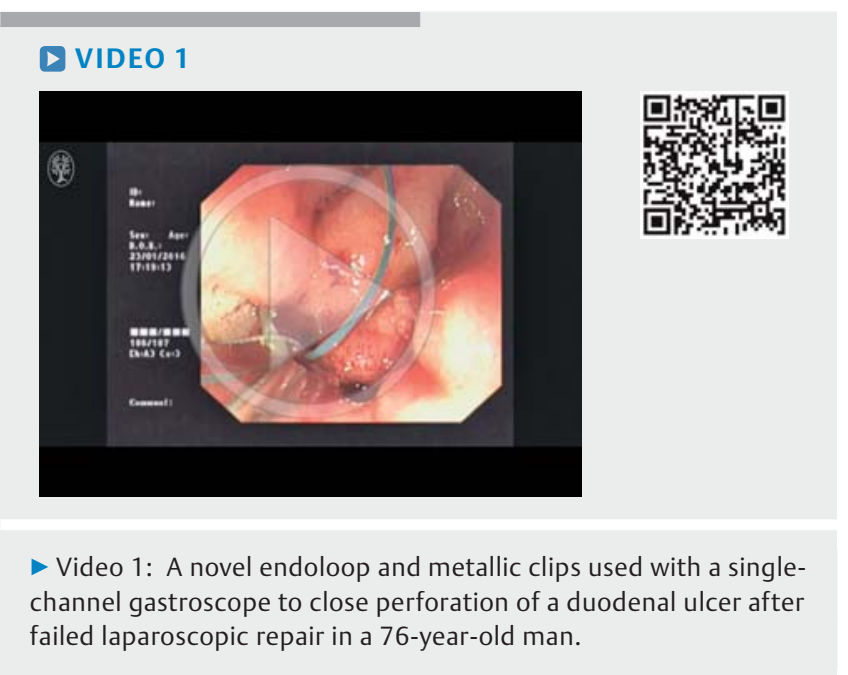



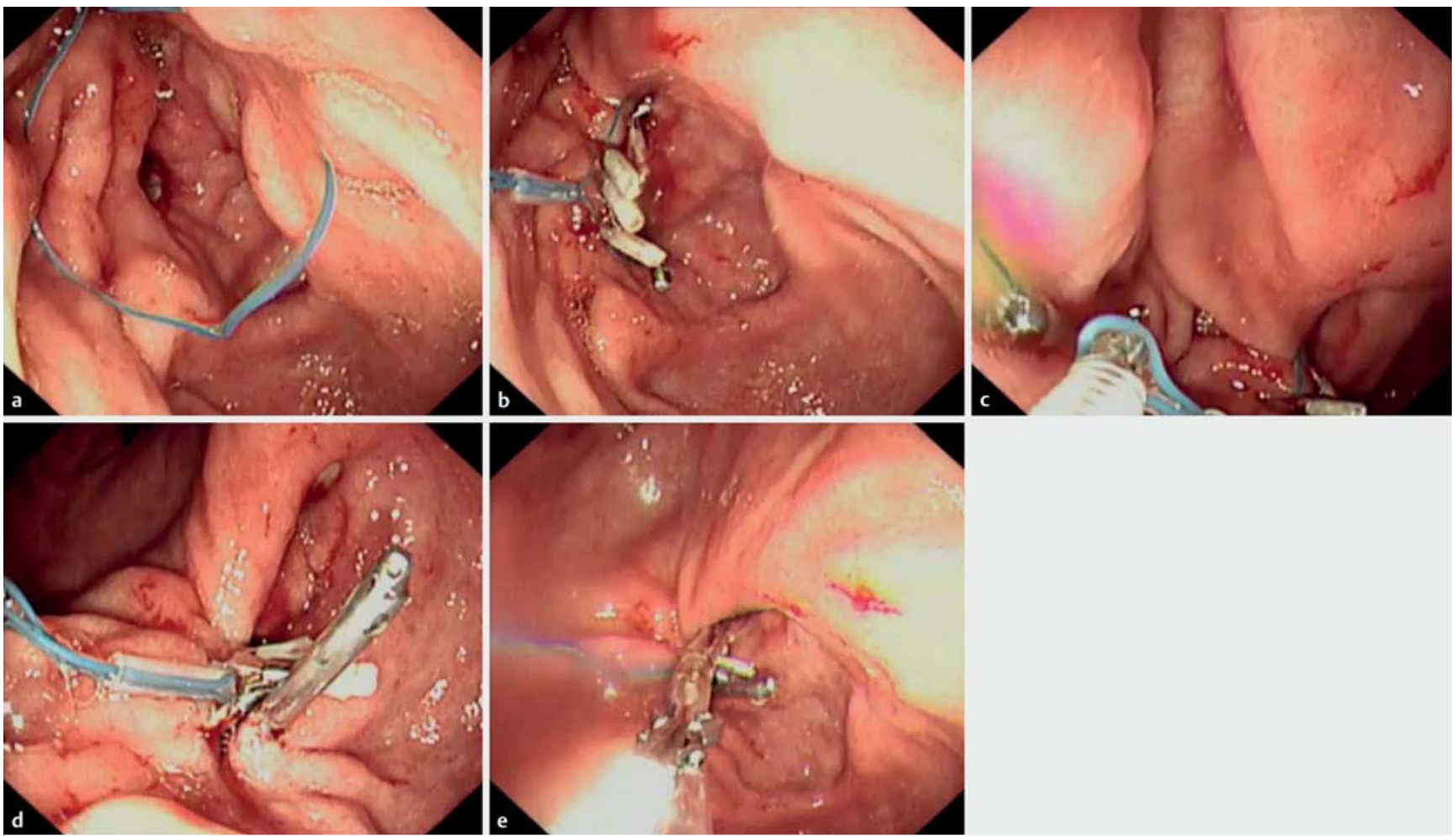

Fig. 3 Closure of duodenal ulcer perforation after failed laparoscopic repair using the novel endoloop with a single-channel gastroscope. a The endoloop was inserted into the duodenal bulb by forceps through the single-channel therapeutic endoscope. b Additional clips were used to hold the endoloop at different points on the edge of the perforation. $\mathbf{c}$ The removable hook that was connected to the endoloop. $\mathbf{d}$ Successful closure of the perforation following tightening of the endoloop by slight pulling together of all the edges. e A gastroduodenal decompression tube was placed as the last step.

The Authors

\section{Shu Huang', Sumin Zhu}

1 Medical Center for Digestive Diseases, People's Hospital of Lianshui, Huaian, China

2 Medical Center for Digestive Diseases, The Second Affiliated Hospital, Nanjing Medical University, Nanjing, China

\section{Corresponding author}

\section{Sumin Zhu, MD}

Medical Center for Digestive Diseases,

The Second Affiliated Hospital, Nanjing Medical University, 121 Jiangjiayuan Road, Nanjing 210011, China

Fax: +86-51-72321458

njzhusumin@163.com

\section{References}

[1] Kim JH, Chin HM, Bae YJ et al. Risk factors associated with conversion of laparoscopic simple closure in perforated duodenal ulcer. Int J Surg 2015; 15: 40 - 44

[2] Shi D, Li R, Chen W et al. Application of novel endoloops to close the defects resulted from endoscopic full-thickness resection with single-channel gastroscope: a multicenter study. Surg Endosc 2016. DOI: 10.1007/s00464-016-5041-4

\section{Bibliography}

DOI http://dx.doi.org/10.1055/s-0042-121488

Endoscopy 2017; 49: E31-E32

(c) Georg Thieme Verlag KG

Stuttgart $\cdot$ New York

ISSN 0013-726X 